\title{
Procesos de modernización y servicios socioculturales para la tercera edad en España
}

\section{Por Miguel JUAREZ GALLEGO(1)}

Hacer que nuestros viejos puedan vivir felices en nuestro mundo actual, es, sencillamente, el mejor índice social de que la sociedad española se ha modernizado y ha cambiado realmente. A ello puede contribuir, sin duda alguna, la dinamización y/o animación sociocultural.

España está experimentando actualmente unos procesos irreversibles de modernización científico-técnica y de cambio social importantes. Es notable que en un período histórico relativamente corto de tiempo haya pasado de ser un pais con estructuras de mentalidad rural a ser un pais con estructuras politicas, económicas, sociales, demográficas y culturales con características más o menos semejantes a las de los países industrializados y urbanizados de la Comunidad Económica Europea. Y es que España, efectivamente, ha cambiado y está cambiando con rapidez y de forma importante ante el asombro de propios y extraños, al configurar un contexto histórico nuevo de modernización y de cambio social generalizado en: la implantación de las nuevas tecnologias, la reorganización de la administración, las innovaciones del empresariado, las novedades ocupacionales de los pro-

(1) Miguel JUAREZ GALLEGO es Subdirector de la Escuela Universitaria de Trabajo Social y Profesor de Politica y Bienestar Social en la Universidad Pontificia Comillas de Madrid. 


\section{Miguel Juarez Gallego}

fesionales, los nuevos sistemas de educación, las transformaciones en la institución familiar, el cambio del rol de la mujer al incorporarse al mundo laboral, la situación, a veces dramática, de la juventud, la importancia cuantitativa y cualitativa de la tercera edad y, finalmente, las nuevas formas de la secularización de la vida en general y de la religión en particular (2).

Nadie duda que la sociedad española está cambiando de forma rápida y que todos esos cambios están produciendo situaciones de desajuste en las estructuras e instituciones de los diferentes grupos sociales. No es mi intención aquí estudiar esos desajustes producidos en el conjunto de la sociedad española, pero sí lo es el referirme al grupo de la población de los mayores de 65 años, fundamentalmente por dos razones. Primero, porque considero que este colectivo de la población ha sido uno de los grupos más castigados por las novedades de los procesos de modernización cientifico-técnica, no sólo de los últimos diez años, sino de los años de guerra civil, del período de postguerra, de los años del desarrollismo económico y, naturalmente, de los años de la crisis de la energia. Y segundo, porque, como consecuencia de lo anterior, la población de la tercera edad necesita que se le haga justicia en términos de política social y se le garanticen unas condiciones de vida en las que su bienestar esté asegurado. Pedir esto es pedir que se adapten las estructuras sociales y culturales a las estructuras políticas y económicas propias de los paises modernos. En este contexto, las personas mayores son el objetivo principal de este estudio, cuyo planteamiento consiste en ver hasta qué punto la dinamización ylo animación sociocultural, tan propia de la nueva mentalidad social del cambio en España, da respuestas concretas de bienestar e integración social a las personas, hombres y mujeres, de la tercera edad.

El hacer de la tercera edad el objetivo principal de este trabajo está motivado por mis propios intereses en conocer hasta qué punto las Instituciones públicas y privadas están respondiendo a los retos sociales más importantes que plantea actualmente la sociedad española. $Y$ uno de esos retos, no el menos importante, lo está planteando la tercera edad, tanto por la importancia numérica de este colectivo, como por la importancia de los problemas y las necesidades que la condición de jubilados genera. Problemas de salud, de identidad per-

(2) Para hacernos una buena idea de todos estos fenómenos del cambio social producido en Espana durante los úttimos años, puede verse el número monográfico de DOCUMENTACION SOCIAL, ¿Ha cambiado España?, N. ${ }^{\circ}$ 65, Madrid, 1986, 222 págs., en el que además se ofrece un apéndice bibliográfico importante sobre todo esté fenómeno. 
Procesos de modernización y servicios socioculturales para la tercera edad en España

sonal, familiar y social, entre otros, piden una serie de atenciones especiales y especializadas, que se deberán atender si realmente un pais quiere ser moderno, humano y civilizado.

Este planteamiento general hace que abordemos este trabajo con una metodologia muy sencilla, que no es otra que la seguida en el orden de la exposición. Teniendo en cuenta que mi interés explicito es hablar de la dinamización sociocultural para la tercera edad considerando el proceso de modernización de España en el que se han "forjado", la estructura de exposición será la siguiente. Primero, hablaré de los aspectos demográlicos que defínen las sociedades modernas con el fin de conocer si la sociedad española está dentro de esas caracteristicas sociodemográficas generales. Segundo, resaltaré algunos as. pectos caracteristicos de los procesos de modernización y cambio social en España con el fin de poder saber en qué situaciones históricas concretas se forjaron las personas consideradas hoy mayores de 65 años. Tercero, haré mención de las principales respuestas oficiales introducidas por el "cambio" para atender a la tercera edad. Cuarto, plantearé la necesidad de atender a la tercera edad en sus necesidades más vitales. Quinto, presentaré la dinamización sociocultural como una respuesta del cambio a las necesidades del tiempo libre para la tercera edad. Y terminaré con las conclusiones y la bibliografía básica utilizada.

\section{Aspectos demográficos de las sociedades modernas}

Para las Ciencias Sociales en general y para la Sociología en particular, uno de los elementos estructurales que mejor muestra el dinamismo de los procesos de modernización y de cambio social en las sociedades desarrolladas es el que corresponde a la estructura de la población en su fase de "transición demográfica", que, según Juan Díz Nicolás, es el proceso mediante el cual una población pasa de altas tasas de mortalidad y de natalidad a bajas tasas de mortalidad y natalidad. Este proceso se ha producido, sigue diciendo J. Diez Nicolás,

"no sólo en épocas diferentes en los diferentes paises según el grado de industrialización, sino que dentro de cada pais se ha producido también en diferentes fechas según el grado de modernización y el estrato socioeconómico de los diferentes subgrupos de la población. La transición demográfica suele tener además unos efectos muy caracteristicos sobre la estructura de la población por sexo y edades. Cuando la mortalidad y la natalidad se 
Miguel Juarez Gallego

encuentran a un nivel bajo, la población envejece, observándose que sólo un 25 por 100 de la población, aproximadamente, tiene menos de quince años, mientras que un 10 por 100 o más supera los sesenta y cinco años" (3).

En el caso de España, al igual que en el resto de las países de la Comunidad Económica Europea, vemos que la forma de la pirámide de población nos aparece como si se hubiera invertido. En ella se aprecia que el número de personas comprendidas entre los grupos de edades de los mayores de 65 años es cada día más importante, mientras que el número de personas comprendidos entre los grupos de edades de los menores de 14 años se reduce cada vez más. Estos hechos nos sitúan ante una estructura de la población en la que el grupo de las personas pertenecientes a la tercera edad adquiere un peso importante dentro del conjunto de la realidad social española, que, según datos del INE, se sitúa actualmente en torno al 12 por 100 (dos puntos por encima del 10 por 100 calculado por J. Díez Nicolás), calculándose además que para el año 2000 se aproximará al 20 por 100 . Esto quiere decir que prácticamente una quinta parte de la población total estará dentro de las personas jublladas que han dejado de ser productivas (me refiero no sólo a las condideradas socioeconómicamente activas, sino también a las que han trabajado como amas de casa), para pasar a ser retiradas y/o pensionistas. Lo cual quiere decir que, dada su condición de inactivas y jubiladas, dispondrán de todo el dia para hacer lo que realmente más les guste.

Relacionada con la importancia cuantitativa de la tercera edad está también la importancia cualitativa. Me refiero a los problemas tan propios de las personas mayores de 65 años. Problemas que se presentan de forma más acentuada al jubilarse, hasta el punto de que esa situación les crea verdaderas crisis de identidad personal, familiar y social, como consecuencia no sólo de dejar de ser personas activas y, por tanto, de no percibir las remuneraciones correspondientes a su trabajo, sino también como consecuencia de no tener nada útil que hacer.

En consecuencia, la "transición demográfica" o bajas tasas de natalidad y bajas tasas de mortalidad es un hecho especifico de las sociedades desarrolladas. Este hecho incide directamente en la estructura y composición de las poblaciones haciendo que haya un número alto de viejos y un número cada vez menor de niños y jóvenes. España está actualmente en un crecimiento demográfico cero, según los da-

(3) Juan DIEZ NICOLAS, "Aspectos demográficos del urbanismo" en Cuadernos para ef Diálogo, N. ${ }^{\circ} \mathrm{XIX}$, Extra de abril, Madrid, 1970, pág. 8. Lo resaltado es mio. 
Procesos de modernización y servícios socioculturales para la tercera edad en España

tos más recientes dados por el INE. Por tanto, España está situada, por pleno derecho, dentro de los paises modernos, industrializados y urbanizados, de acuerdo con su estructura demográfica. Lo cual no deja de ser un problema que empieza a preocupar a los organismos públicos cuando piensan en el año 2020. Pero veamos quiénes son y dónde han crecido nuestros mayores de hoy, puesto que, en definitiva, ellos son los que están necesitando nuestras atenciones.

\section{La historia que ha "forjado" a la tercera edad de hoy}

Es lógico pensar que España se ha modernizado y ha cambiado no de forma improvisada, sino como consecuencia de un proceso histórico que podemos acotar en un periodo de aproximadamente treinta años. Ese proceso empezaba más o menos a finales de los años cincuenta y se potenciaba durante la década de los años sesenta, precisamente como consecuencia de aceptar los retos de la industrialización y la urbanización de los Planes de Estabilización y de Desarrollo Económico y Social (4), a los que siguieron los periodos de la Transición y la Estabilidad Democrática. Nuestros mayores de hoy crecieron y se "forjaron" dentro de ese gran marco.

Aunque es verdad que nunca en la historia de España se ha hablado tanto de modernización y cambio social como en los últimos años, sin embargo, esos procesos empezaron a gestarse muchos años antes. Ya a finales del siglo XIX, pero sobre todo en el primer tercio del siglo xx España empezaba a cambiar sensiblemente. Aumentaba la industria y crecían las ciudades como consecuencia del aumento de la emigración de la gente del campo que se iba a trabajar y a vivir a las ciudades. Asi resultaba que en 1936 aproximadamente el 40 por 100 de los habitantes de las grandes ciudades habian nacido en otro municipio distinto al de su residencia habitual, pues habian venido a las cludades atraidos por las posibilidades de trabajo, de ocupación permanente y de mejor remuneración. Todo lo cual hizo que se produjeran unos desajustes importantes entre el número de habitantes que se asentaba en los nuevos espacios habitables y los equipamientos de los servicios urbanos; en la mayoría de los casos se carecia de los más elementales. Véanse, por ejemplo, las carencias de los servicios de sanidad, educación, ocio y tiempo libre, por citar algunos de los más importantes y necesarios (5).

(4) Amando de MIGUEL, Estructura social de España, Ed. Tecnos, Madrid 1974, apartados 2.3 y 3.4, pp. 94-131 y 178-192.

(5) Miguel JUAREZ, Tetuán ayer y hoy, Cambios urbanisticos y desigualdades sociales. Ed. Ayuntamiento de Madrid y Universidad Pontificia Comillas, Madrid, 1989. Pue- 


\section{Miguel Juarez Gallego}

En 1936 empezaba la guerra civil española y con ella un periodo duro y dirícil para la población. Una vez terminada, la población de España se habia empobrecido y comenzaba el periodo de la "Reconstrucción". Rafael Abella nos cuenta muy realistamente cuáles eran las condiciones socioeconómicas en las que vivia la gente durante el período del franquismo en su libro La vida cotidiana en España bajo el régimen de Franco. Se resalta sobre todo la situación de "miseria, hambre y estraperlo" que caracterizó el periodo de los años cuarenta y cincuenta (6). Tras el periodo de recuperación económica y amortiguamiento de las tendencias autárquicas (1951-1956), se inicia un camino de búsqueda de un nuevo equilibrio mediante el Plan de Estabilización (1957-1960) y de Desarrollo Económico y Social (1961-1973). En torno a 1973 se acentuaba la crisis de la energia (7). Si el Plan de Estabilidad y los Planes de Desarrollo Económico y Social significaron para España su incorporación definitiva a los procesos de modernización económica, no significaron 10 mismo para los procesos de modernización política y social.

Durante ese período se vivía en España un ambiente de cierta euforia "desarrollista" que se vio truncada por la aparición de la crisis energética de 1973. A esa crisis hay que sumar además la situación de crisis política de los últimos años del franquismo. Tras la muerte de Franco empezaba un período de transición politica hacia la Democracia Parlamentaria. En 1978 se aprobaba la Constitución Española y con ella se garantizaban los derechos y las libertades de todos los ciudadanos españoles. Era el momento de la "Estabilidad Política" capitaneada por los Presidentes Arias, Suárez y Calvo Sotelo, cuyos errores y aciertos será la historia la que se encarge de valorar, pero, a la vez, era el comienzo de la gran crisis del "paro estructural" que se potenciaría con el fenómeno de la reconversión industrial y cuyos verdaderos "perdedores" fueron muchos de los que, años atrás, habian venido de sus pueblos para trabajar en los principales centros de producción industrial, sin apenas cualificación profesional, que pasarian a engrosar las listas de los parados o de la jubilación anticipada.

den verse los capítulos segundo y tercero. De Miguel JUAREZ puede verse también, Urbanismo marginal y práctica pastoral en Ja periferia madrileña, UPC, Madrid, 1981, es. pecialmente el capitulo de la importancla de los movimientos migratorios en la configuración del urbanismo periférico madrileño. Y J. SANCHEZ JIMENEZ, "La población, el campo y las ciudades", en Historia de España, Menéndez Pidal, Tomo XXXVHI, Madrid, 1984, págs. 230-ss.

(6) Rafael ABELLA, La vida cotidiana en España bajo el régimen de Franco, Ed. AFgos Vergara, Barcelona, 1984. 241 págs.

(7) Ramón TAMAMES, La República. La Era de Franco. Alianza Universidad, Madrid, págs. 461-472. 
Procesos de modernización y servicios socioculturales para la tercera edad en España

Superada la era del "suarismo" aparecia la era del "felipismo" con el lema "POR EL CAMBIO" y prometiendo la creación de 800.000 puestos de trabajo. En las elecciones de 1982 triunfaba el partido socialis. ta con una mayoria aplastante. Este hecho significó algo tan importante como apostar por la modernización y el cambio. Para ello debia empezarse por reformular las estructuras políticas, económicas, sociales, culturales y las mentalidades de la gente. Debian aceptarse los retos de la reindustrialización y de las "nuevas tecnologias", aun sabiendo que ello supondría unos costos sociales muy importantes. La sociedad española queria y quiere la modernización y el cambio y, aunque con ciertos temores, estaba y está dispuesta, a soportar los costos que ello conlleva, porque entiende que ese es el mejor camino entre todos los posibles. Sabe, además, que la aceptación de la implantación de las "nuevas tecnologias" significa acelerar el cambio entre las diferentes generaciones (jóvenes, adultos, viejos), reduce las diferencias de hombre/mujer, y se reestructuran las clases y estratos sociales. En consecuencia, nuestra sociedad, con sus más y sus menos, acepta las "nuevas tecnologías" porque está segura que eso significa modernización, progreso, y bienestar social para todos (8), y yo me atreveria a decir que ello significa bienestar social muy especialmente para la tercera edad, ya que este colectivo de nuestra población es. tá teniendo unas atenciones muy merecidas, aunque insuficientes, no sólo en el campo asistencial de seguridad a la vejez, sino sobre todo en el campo de la animación sociocultural. Y este aspecto sí que es absolutamente nuevo del cambio.

\section{Respuestas oficiales desde el cambio para atender a la tercera edad}

Las situaciones sociales de la tercera edad creadas por los procesos de modernización de las nuevas tecnologias y del cambio sociopolítico no podian ser ignoradas por la administración de los sectores públicos o de los sectores privados. Muchas personas mayores, bien porque habian cumplido los 65 años o bien porque habian sido jubiladas anticipadamente, se veían desprotegidas económica, social y culturalmente. En ese contexto surgen respuestas oficiales de todo

(8) Manuel CASTELLS y otros, El desafío tecnológico. España y las nuevas tecnologias. Alianza Editorial, Madrid, 1986. Tambièn pueden verse en el PROGRAMA 2000 de PSOE, La economia española a debate y La sociedad española en transformación. Ed. Siglo XXl, Madrid, 1988. Y Miguel ROIZ, "Nuevas tecnologías y transtormación de la es. tructura social española", en Documentación Social, N. “65, Madrid, 1986, págs. $31-54$ Y J FELIX TEZANOS "Camblo social y modernización en la España acutal" en Revista Española de Investigaciones Sociológicas, N. ${ }^{\circ} 28$, Madrid, 1984, págs. 19-62. 


\title{
Miguel Juarez Gallego
}

tipo. Una de ellas, y no la menos importante, es la que se da desde los proyectos politicos, orientada a promover unos objetivos amplios de bienestar social. Y así, la Constitución Española de 1978, el proyecto politico más importante del cambio, garantiza el blenestar social para todos los españoles en su Título I, capitulo tercero, en su intento de superar la etapa anterior. Y esa misma garantia es recogida después por los organismos administrativos de las Comunidades Autónomas, las Diputaciones y los Ayuntamientos, quienes, además de asumir la Constitución, asumen también el Artículo 25.1 de la Declaración Universal de los Derechos Humanos de 1948 que se expresaba en los siguientes términos:

\begin{abstract}
"Toda persona tiene derecho a un nivel de vida adecuado que le asegure, asi como a su familia, la salud y el bienestar, en especial la alimentación, el vestido, la vivienda, la asistencia médica y los servicios sociales necesarios; tiene asimismo derecho a los seguros en caso de desempleo, enfermedad, invalidez, viudedad, vejez y otros casos de pérdida de sus medios de subsistencia por circunstancias independientes de su voluntad".
\end{abstract}

En el caso concreto de la Constitución Española, en el Artículo 50 se señalan las novedades del cambio respecto a los derechos de los anclanos:

"Los poderes públicos garantizarán, mediante pensiones adecuadas y periódicamente actualizadas, la suficiencia económica de los ciudadanos durante la tercera edad. Asimismo, promoverán su bienestar mediante un sistema de servicios sociales y atenderán sus problemas especificos de salud, vivienda, cultura y ocio".

Bienestar social en el sentido más amplio de la expresión, juntamente con el derecho al ocio y la cultura son dos realidades muy presentes que los programas de los servicios públicos están dispuestos a llevar a cabo en sus actuaciones con la tercera edad. Para ello se han configurado una serie de centros de atención al pensionista, al jubilado y en general a la población de los mayores, tales como residencias, hogares, clubs, centros de recreo y de animación sociocultu. ral. Este tipo de atenciones específicas a la tercera edad es, sin duda, una de las novedades más importantes de los últimos años, aunque por otra parte reconozcamos que ya existían anteriormente algunas de ellas con orientaciones, objetivos y planteamientos más o menos parecidos.

En honor a la verdad, hemos de reconocer que este aspecto de atención a la tercera edad se ha potenciado mucho en los últimos años. 
EI PSOE, partido mayoritario actualmente en el Parlamento y en el Gobierno del Estado, ha expuesto sus principios en cuanto a bienestar social, jubilación, prestaciones económicas y protección de la salud y actualización de la animación sociocultural en la tercera edad. Es cierto que el desarrollo de ese programa se encuentra actualmente en una fase inicial, pero es igualmente cierto que existe voluntad expresa de considerarlo entre sus prioridades. Existe, por tanto, un interés notable por prestar atención especial y especializada a la población de los mayores, no sólo dotándoles de los recursos económicos necesarios (mejoras en las pensiones), sino además mediante la dotación de recursos materiales, humanos y culturales que hagan posible que los jubilados y pensionistas se sientan y se encuentren realmente más integrados dentro de la sociedad española del cambio. Esa y no otra es la finalidad explícita pretendida con la creación de un gran número de "Centros para la Tercera Edad" que está llevando a cabo el INSERSO (9).

\section{Problemas especificos de la tercera edad a tener en cuenta por la dinamización sociocultural}

Aunque resulte algo reiterativo creo necesario recordar algo que ya hemos comentado en apartados anteriores, con la única finalidad de conseguir una mayor claridad expositiva. En el apartado primero veíamos la importancia cuantitativa del colectivo de la tercera edad. Ella representaba aproximadamente un 12 por 100 de la población total; hombres y mujeres que han cumplido los 65 años y que, por otra parte, prácticamente de la noche a la mañana, han dejado de ser per. sonas socioeconómica y socioprofesionalmente activas para conver. tirse en jubilados ylo pensionistas. Veíamos también, en el apartado segundo, que esas personas crecieron, trabajaron y vivieron en un etapa de la historia de España en la que las condiciones sociopoliticas, socioeconómicas y socioculturales no eran precisamente las más adecuadas para el confort o el bienestar. Ellos, en terminología de Rafael Abella, son los que vivieron los períodos de "hambre, miseria y estraperlo". Ellos son los que durante los años difíclles emigraron del campo a la ciudad. Y ellos son los que no pudieron, o pudieron a medias, asistir a la escuela y adquirir un cierto nivel cultural. Ellos son, en definitiva, los que han pagado unos costos mayores por la moder-

(9) Para valorar la importancia de esta afimación puede consultarse la obra publicada por el INSTITUTO NACIONAL DE SERVICIOS SOCIALES (INSERSO), Análisis de la Guja de Centros para la Tercera Edad, Ed. Ministerio de Trabajo y Seguridad Social, INSERSO, Madrid, 1987. 317 págs. 
Miguel Juarez Gallego

nización y por el cambio de España no sólo en el periodo del franquismo, sino también en el período del felipismo. Son los hijos del desarrollismo y de la reindustrialización. Pues bien; toda esta gente es la que con el paso de su condición de activos a inactivos, sufre en su mayoria, una pérdida de identidad personal, familiar y social. $Y$ esa pérdida de identidad tiene unas repercusiones básicas en sus vidas de viejos a tres niveles principales: psíquico, biológico y de relaciones sociales. Este conjunto de problemas, derivados de su propia condición, son los que debemos conocer y tener en cuenta cuando planteemos cómo ayudarles en sus problemas y necesidades.

Desde el punto de vista psiquico y biológico, las personas viejas se consideran a si mismas especiales. Ellos mismos ven reducidas en gran medida sus propias capacidades psíquicas y biológicas, que suelen manifestarse en las siguientes características objetivas: aparecen como personas inseguras en todas sus actuaciones y movimientos, se muestran prudentes, conservadoras, pasivas, introvertidas, perseverantes, egoístas, dependientes, conformistas y ordenadas. Pero además, junto a estas características aparecen otras que muestran el deterioro de su inteligencia, la disminución de su memoria, el aprendizaje, las habilidades perceptivo-motrices y las emocionales (10).

Estos factores de tipo psiquico y biológico hacen que las personas mayores se experimenten a si mismas distintas, con pérdida de identidad personal, familiar y social. Se sienten inseguras y ello repercute en sus relaciones sociales. Lo cual les provoca situaciones de soledad, dificultades de adaptación, insatisfacción personal y excesivo tiempo libre, contribuyendo a que se acentúe el deterioro progresivo de su organismo. Y como resultado de esas características de índole psíquica, biológica y de relaciones sociales, las personas de la tercera edad pierden interés e ilusión por la vida.

Hemos de tener en cuenta, por otra parte, que nuestros mayores tienen un escaso nivel educativo, lo cual es un factor importante a valorar cuando tratemos de pensar en qué y cómo podemos establecer planes de dinamización sociocultural para esta población. En general se constata que su interés por la cultura es escaso so pretexto de que "a mis años ya me lo sé todo", pero además por las características

(10) VARIOS, Envejecimiento biológico y salud, Ed. Caja de Ahorros de Madrid, Ma drid, 1986. 241 págs.. Rosa LOPEZ MONGIL, Consideraciones epidemiológicas y sociales de un grupo de la tercera edad. Ed. Diputación de Valladolid, Madrid, 1987. 155 págs. Otro libro muy valioso en este sentido es el de SOLIDARIDAD DEMOCRATICA, Consumo de sustancias tóxicas en la tercera edad. Estudio sociológico, Ed. Instituto Nacional de Estudios Sociales, Madrid, 1987. 348 págs. 


\section{Procesos de modernización y servicios socioculturales para la tercera edad en España}

históricas en las que vivieron. No olvidemos que nuestros viejos de hoy son, en su mayor parte, aquellos hombres y mujeres que durante los años de desarrollismo económico y social de los años sesenta emigraron del campo a la ciudad y su nivel educativo-cultural era y es muy bajo. No creo que sea este el caso de dar cifras, pero el analfabetis. mo o el escaso número de años pasados en la escuela es una realidad muy común entre este colectivo. Por eso no nos extraña la falta de interés por la cultura en general. Sin embargo, creo que deben proponerse fórmulas válidas para que toda esa población tenga en qué dedicar su tiempo libre de forma creativa y recreativa en los talleres de animación sociocultural existentes actualmente o en los que se implantan en el futuro.

\section{La dinamización sociocultural como respuesta de integración globalizante para la tercera edad}

Ya hemos visto quiénes son nuestros mayores. Sabemos ya dónde han madurado y cuáles son las caracteristicas psiquico-biológicas y de relaciones sociales que más les afectan cuando llegan a esa situación de personas de la tercera edad. Ahora trataremos de ver si efectivamente la dinamización y/o la animación sociocultural puede ser una forma "nueva" que dé respuesta de sentido integrador a su falta de identidad personal, familiar y social. En este sentido, primero hablaremos de qué se entiende por animación sociocultural en general, para posteriormente ver si responde o no a las necesidades de la tercera edad.

En un sentido muy general se ha dicho que la dinamización y/o anmación sociocultural consiste en "elaborar modelos de intervención que permitan establecer proyectos concretos de acción dinamizadora de los diferentes grupos sociales" (11). La finalidad de estos proyectos es que determinados grupos sociales ejerciten un cierto dinamismo educativo-cultural de forma que les posibilite el cambio no sólo social, sino también de actitudes, mentalidad y aun de valores. Podemos decir que este tipo de acción dinamizadora de los grupos sociales es una forma nueva que ha surgido como consecuencla de querer que se participe activamente en la vida educativa y cultural de nuestra sociedad actual. No es nueva en otros sentidos de intervención, tales como la culturización, contestación e incluso socialización de

(11) Carmina GOMEZ PEREZ, "La Animación sociocultural. Conceptos fundamentales", en Documentación Social, N. ${ }^{\circ}$ 70. Madrid 1987, pág. 11. 


\title{
Miguel Juarez Gallego
}

la juventud (12); pero si es nueva, del periodo democrático, respecto a la tercera edad española, que tiene las caracteristicas especificadas reiteradas, a la que con todo acierto puede aplicársele tanto en el sentido más arriba mencionado, como en el sentido que señala $P$. Bernard sobre todo en las primeras líneas que transcribo a continuación:

\begin{abstract}
"La animación sociocultural, ¿de qué se trata? Para unos se trata de un modo de organización del ocio a la sombra de las técnicas recreológicas norteamericanas, con una concepción ocupacional del tiempo libre de los individuos. Para otros es un movimiento social de emancipación de las masas a través de una verdadera cultura popular para asegurar una continuidad de la ideologia participacionista que permite una revolución social sin conflictos y por otra parte un instrumento de subversión. Para los animadores técnicos y profesionales, es la ocasión de trabajar en la cultura y hacer remunerar su creación, difundiéndola a través de instituciones socioculturales innumerables. Para los militantes, la posi. bilidad de afirmar su ideal de hacer participar en sus ideales a sus neurosis'. Para los ediles locales es la ocasión de extender su poder o de perderlo, es la manera de paliar sus preocupaciones socloculturales o de resolver los problemas de las grandes empresas para prevenir la delincuencia. Para la critica social es un instrumento privilegiado para los que proyectan sus esperanzas revolucionarias decepcionados y plensan crear un verdadero poder cultural" (13).
\end{abstract}

Creo que en el caso de la tercera edad la animación sociocultural debe ser, como dice P. Bernard al principio de su definición, un modo de organización del ocio a la sombra de técnicas recreológicas..., con una concepción ocupacional del tiempo libre de los individuos". En ese sentido, la dinamización sociocultural puede responder adecuadamente y disfrutando con lo que ellos quieran hacer. Esa, me parece a mi, es la mejor forma de hacer que nuestros mayores sientan inquietud por lo cultural, pues debemos tener en cuenta que, efectivamente, ya están de vuelta de todo y lo que ahora necesitan es disfrutar ha. ciendo lo que realmente les guste. Ya no se trata de "culturizar" a base de esfuerzo y trabajo y mucho menos de mentalizar a nadie de nada. De lo que se trata es de hacer que las personas mayores saboreen

(12) Para ver otras formas de animación sociocultural distinta a la actual, puede consultarse Carmina GOMEZ PEREZ, op. cit., págs. 13-15.

(13) Plerre BERNARD. L'Animation Socio-culturelle, págs. 7-8. Cita sacada de Carmina GOMEZ LOPEZ, op. cit. pág. 16. El resaltado es mio porque creo que se ajusta muy bien a la intencionalidad de este trabajo. 


\section{Procesos de modernización y servicios socioculturales para la tercera edad en España}

las oportunidades perdidas. De lo que se trata es de que vivan su presente saboreando su pasado. Por eso, el animador sociocultural debe tener en cuenta que al mayor le gusta revivir su pasado, mostrar sus actividades folklóricas, manuales y artesanales, sin que esto signifique, en ningún caso, que se les considere como un grupo aparte. Se ha de tener en cuenta que la cultura que ellos quieren y desean es aquella de la que ellos mismos pueden ser los protagonistas. Debe ser una cultura creativa que les ayude a ser ellos mismos. Más que montar espectáculos para la tercera edad, deberían hacerse espectáculos con la tercera edad. Nadie mejor que ellos saben lo que les interesa. Eso les ayudará a sentirse integrados en su mundo, se sentirán útiles, disfrutarán con lo que hacen, se sentirán queridos y acogidos, se olvidarán de sus artrosis y vivirán la vida con ilusión y optimismo. No se sentirán olvidados sino que se sentirán acogidos.

\section{CONCLUSION}

Por todo esto, mi conclusión final es èsta. Teniendo en cuenta las características del entorno histórico de la modernización y del cambio sociopolítico en el que los hombres y mujeres de la tercera edad de España se han forjado y teniendo en cuenta los problemas que son especificos de su edad, los animadores y dinamizadores socioculturales deberán organizar actividades que se encuadren dentro de aquellas áreas socioculturales que más se adecúen a sus propios intereses. Esas áreas de dinamización socioculturales pueden ser las síguientes: el área de cultura física para atender a sus problemas corporales, el área de humanidades para atender a sus intereses intelectuales, el área de talleres para atender a sus intereses creativomanuales, el área de animación comunitarla y el área social para que cultiven sus cualidades relacionales de encuentros y diálogos. No olvidar que por encima de todo está su libertad para que cada cual participe en el área que más le guste hacerlo (14).

Estoy seguro que si esto se hace asi, las personas mayores se sentirán valoradas en toda la riqueza humana que ellas poseen. Verán que se aprecia su trabajo o su colaboración y se sentirán útiles precisa-

(14) En este sentido puede verse un articulo muy claro de Angel de CASTRO, "La Animación sociocultural", en 60 y Más, N. ${ }^{\circ} 41$, Madrid, t988, págs. 10-11. E igualmente los libros del INSTITUTO IDES, Programa de vacaciones para la tercera edad. Estudio sociológico. Ministerio de Trabajo y Seguridad Social. Instituto Nacional de Servicios Sociales, Madrid, 1987. Y GOBIERNO VASCO, Ancianos en residencias, Servicio Central de Publicaciones del Gobierno Vasco, Vitoria, 1985. 
mente cuando, como ellos piensan, la sociedad del cambio, al jubilarlos, los considera inútiles. Por tanto, más importante que lo que ellos hagan será cómo se les sabe valorar to que hagan. Esos gestos de atención, de acogida y, en definitiva, de saber que no son unos seres extraños en medio de la sociedad que les ha hecho ser lo que son, será razón más que suficiente para que ellos se sientan plenamente integrados y vivan con verdadero sentido su vida creativa en su mundo y siempre y no como las personas que "ya no sirven para nada".

Creo, finalmente, que la animación sociocultural tal y como está planteada hoy en los múltiples centros que ya existen debe hacer posible esa realidad. $Y$ a la administración pública, por su parte, le corresponderá el proporcionar cuanta ayuda sea necesaria para que los centros de tercera edad sean cada día una realidad más adecuada a sus propias necesidades. Hacer que nuestros viejos puedan vivir fellces en nuestro mundo actual, es, sencillamente, el mejor índice social de que la sociedad española se ha modernizado y ha cambiado realmente. A ello puede contribuir, sin duda alguna, la dinamización y/o animación sociocultural.

\section{BIBLIOGRAFIA}

ABELLA Rafael, La Vida Cotidiana en España bajo el Régimen de Franco, Ed. Argos Vergara, Barcelona, 1984. 241 págs.

BARACCO L., "L'Anziano in una società che cambia", en Aggionarmenti Sociali, $\mathrm{N}^{\circ}{ }^{\circ}$ 3, Milano, 1988, págs. 189-204.

CASTELLS Manuel y Otros, El Desafio Tecnológico. España y las Nuevas Tecnologias. Alianza Editorial, Madrid, 1986. 407 págs.

DIEZ NICOLAS Juan, "Aspectos Demográficos del Urbanismo", en Cuadernos para el Diálogo, N. ${ }^{\circ}$ Extra, Abril, 1970, págs. 8-11.

CARITAS ESPAÑOLA, "Animación Sociocultural. Modelos Operativos", en Documentación Social, N. ${ }^{\circ}$ 70, Monográfico, Madrid, 1987. 234 págs.

CARISTAAS DIOCESANA, La 3. Edad en la Provincia de Madrid, Ed. Cáritas Diocesana, Madrid, 1979. 246 págs.

CASTRO Angel de, "La Animación Sociocultural" en 60 y más, . 41, INSERSO, Madrid, 1988, págs. 10-11. 
Procesos de modernización y servicios socioculturales para la tercera edad en España

FELIX TEZANOS J., "Cambio Social y Modernización en la España Actual" en Revista Española de Investigaciones Sociológicas, N. ${ }^{\circ} 28$, Madrid, 1984, págs. 19-62.

GARCIA HERRERO Gustavo, Los Centros de Servicios Sociales. Conceptualización y Desarrollo Operativo. Ed. Siglo XXI., Madrid, 1988. 405 págs.

GAUR Informe. La Situación del Anciano en España. Ed. Confederación Española de Cajas de Ahorros. Madrid, 1975. 718 págs.

GOBIERNO VASCO, Elementos Conceptuales para una Politica de Atención a la Tercera Edad. Ed. Servicios Centrales de Publicaciones del Gobierno Vasco, Vitoria, 1988. 83 págs.

_- - Ancianos en Residencias. Ed. Servicios Centrales de Publicaciones del Gobieno Vasco, Vitoria, 1985. 235 págs.

GOMEZ PEREZ Carmina, "La Animación Sociocultural. Conceptos Fundamentales", en Documentación Social, N. ${ }^{\circ}$ 70, Madrid, 1987, págs. $11-32$.

HERAS Patrocinio de las, Introducción al Bienestar Social. Ed. Federación de Asistentes Sociales, Madrid, 1958.

INSERSO, Análisis de la Guía de Centros pra la Tercera Edad, Ed. Ministerio de Trabajo y Seguridad Social, INSERSO, Madrid, 1987. 319 págs.

INSTITUTO IDES, Vacaciones Tercera Edad. Estudio Sociológico. Ed. Ministerio de Trabajo y Seguridad Social. Madrid, 1987. 187 págs.

JUAREZ Miguel, Tetuán Ayer y Hoy. Cambios Urbanísticos y Desigualdades Sociales. Ed. Ayuntamiento de Madrid y Universidad Pontificia Comillas, Madrid, 1989. 450 págs.

_-_.., Urbanismo Marginal y Práctica Pastoral en la Periferia Madrileña, Memoria de Licenciatura, Universidad Pontífica Comillas, Madrid, 1981. 276 págs. (En trámite de publicación).

KREPS Juanita M. y otros, Employment, Income, and Retirement Problems of the Age. Duke University Press, Durham, North Carolina, 1963. 240 págs.

LOPEZ MONGIL Rosa, Consideraciones Epidemiológicas y Sociales de un Grupo de la Tercera Edad. Ed. Diputación de Valladolid, Madrid, 1987. 155 págs. 
MIGUEL Amando de, Estructura Social de España. Ed. Tecnos, Madrid, 1974. 590 págs.

PASSANANTE M. ${ }^{a}$ Inés, Politica Social de la Tercera Edad. Ed. Humanitas, Buenos Aires, 1983. 175 págs.

SOLIDARIDAD DEMOCRATICA, Consumo de Substancias Tóxicas en la Tercera Edad. Estudio Sociológico. Ed. Instituto Nacional de Estudios Sociales, Madrid, 1987. 348 págs.

PSOE, "La Economía Española a Debate", en PROGRAMA 2000, Ed. Siglo XXI, Madrid, 1988. 177 págs.

PSOE, "La Sociedad Española en Transformación", en PROGRAMA 2000, Ed. Siglo XXI, Madrid, 1988. 189 págs.

ROIZ Miguel, "Nuevas Tecnologías y Transformaciones de la Estructura Social Española", en Documentación Social, N. ${ }^{\circ} 65$, Madrid, 1986, págs. 31-54.

SANCHEZ JIMENEZ José, "Cambios y Permanencias en la Espa" ña Contemporánea", en Documentación Social, N. ${ }^{\circ} 65$, Madrid, 1986, págs. 9-30.

TAMAMES Ramón, La República. La Era de Franco. Alianza Universidad, Madrid, 617 págs.

VARIOS, Envejecimiento Biológico y Salud. Ed. Caja de Ahorros de Madrid, Madrid, 1986, 241 págs. 